\title{
Contratación de obreros municipales de Chachapoyas (Amazonas, Perú) y sus derechos laborales, 2017-2018
}

Hiring of municipal workers in Chachapoyas (Amazonas, Peru) and their labor rights, 2017-2018

\author{
Yoselith S. Rojas-Rojas \\ ORCID: 0000-0002-3557-347X \\ Universidad Nacional Toribio Rodríguez de Mendoza de Amazonas, Perú \\ Correo: sareli.rojas.epg@untrm.edu.pe \\ Pilar Mercedes Cayllahua Dioses \\ ORCID: 0000-0001-8617-6215 \\ Universidad Nacional Toribio Rodríguez de Mendoza de Amazonas, Perú \\ Correo: pilar.cayllahua@untrm.edu.pe
}

Recibido: 10/08/2021

Aceptado: 07/09/2021

Resumen: El presente artículo se realizó en marco de una tesis formulada y sustentada en la Universidad Nacional Toribio Rodríguez de Mendoza de Amazonas (Perú), tuvo como objetivo demostrar que las modalidades de contratación en obreros municipales han generado una problemática a nivel nacional. Se pretendió identificar los derechos laborales vulnerados en la contratación de obreros en la Municipalidad Provincial de Chachapoyas (MPCh), región Amazonas (Perú), a través del análisis de los contratos suscritos entre el trabajador obrero y la MPCh durante los años 2017 y 2018. Se obtuvo como resultado que los contratos suscritos infringen las disposiciones descritas en el párrafo segundo del artículo 37 de la Ley 27972 con consecuencias que vulneran los derechos laborales de los trabajadores obreros, siendo estos la estabilidad laboral y el pago de beneficios sociales, como gratificaciones, asignación familiar y compensación por tiempo de servicios. Además, se discuten las implicancias de esta vulneración en el contexto de la normativa nacional.

Palabras clave: beneficios sociales; estabilidad laboral; Ley Orgánica de Municipalidades; vulneración de derechos.

Abstract: This article was carried out within the framework of a thesis formulated and supported at the Universidad Nacional Toribio Rodríguez de Mendoza de Amazonas (Peru), its objective was to demonstrate that the modalities of hiring municipal workers have generated a problem at the national level. It was intended to identify the labor rights violated in the hiring of workers in the Provincial Municipality of Chachapoyas (MPCh), Amazonas region (Peru), through the analysis of the contracts signed between the worker and the MPCh during the years 2017 and 2018. The result was that the signed contracts violate the provisions described in the second paragraph of article 37 of Law 27972 with consequences that violate the labor rights of bluecollar workers, these being job stability and the payment of social benefits, such as bonuses, family allowance and compensation for time of service. In addition, the implications of this violation are discussed in the context of national regulations.

Keywords: social benefits; labor stability; Organic Law of Municipalities; violation of rights.

Cómo citar: Rojas-Rojas, Y. S., \& Cayllahua-Dioses, P. M. (2021). Contratación de obreros municipales de Chachapoyas (Amazonas, Perú) y sus derechos laborales, 2017-2018. Revista de Derecho, 24, 216-233. https://doi.org/10.22235/rd24.2655 


\section{Introducción}

Desde 1919, la Organización Internacional del Trabajo (OIT) ha sido el ente rector de la regulación jurídica laboral a nivel mundial (OIT, 2009). Esta institución ha permitido establecer relaciones laborales entre el empleador y el trabajador (Ministerio de Trabajo y Promoción del Empleo [MTPE], 2016), y ha resultado importante para el ordenamiento jurídico peruano. La normativa nacional, en marco de convenios internacionales de la OIT (convenio sobre igualdad de remuneración (100), vacaciones pagadas (52), entre otros) y demás mecanismos jurídicos, ha logrado regular ampliamente (Ley 28518, 30222, entre otras) los deberes y derechos laborales para el sector público y privado.

En afán por proteger al trabajador, el Estado peruano ha establecido diferentes regímenes laborales, en donde cada régimen implica el reconocimiento de diferentes derechos y deberes. Actualmente, en Perú existen 40 regímenes laborales, de los cuales 15 son aplicables a entidades del gobierno estatal (Autoridad Nacional del Servicio Civil [Servir], 2012). De los 15 regímenes laborales aplicables a entidades del gobierno estatal, los servidores y funcionarios de los gobiernos locales o municipalidades se sujetan bajo tres de ellos, a saberse: el Decreto Legislativo (D. L.) 276, conocido como régimen público; Decreto Legislativo (D. L.) 728, conocido como régimen privado; y la Contratación Administrativa de Servicios (CAS; D. L. 1057).

De manera particular, los Trabajadores Obreros Municipales (TOM), según lo dispuesto en el segundo párrafo del artículo 37 de la Ley Orgánica de Municipalidades (LOM, Ley 27972) son reconocidos como servidores públicos sometidos únicamente bajo el régimen laboral del D. L. 728. La Corte Suprema de Justicia (CSJ) y el Tribunal Constitucional (TC) confirman esta condición para los TOM. La CSJ ha fijado precedentes de obligatoria observancia donde todo trabajador obrero municipal necesariamente debería sujetarse al régimen de la actividad privada, regulado por la Ley de Productividad y Competitividad Laboral, aprobado por Decreto Supremo (D.S.) 003-97-TR. ${ }^{1}$ Por su parte, el TC ha emitido criterios jurisprudenciales en reiteradas ocasiones, indicando que las actividades realizadas por un obrero contratado por una municipalidad son protegidas por el régimen privado, según lo establecido en los fundamentos del expediente 01582-2016-PA/TC.

Sin embargo, resulta innegable la situación de precariedad institucional y las condiciones de inestabilidad laboral que afrontan los trabajadores obreros municipales (TC, 2015). Por ejemplo, al 31 de marzo de 2018, el 24.52 \% (16930) de los TOM de Perú fueron contratados bajo la figura de contratación por locación de servicios; mientras que, en el departamento de Amazonas, de los

\footnotetext{
${ }^{1}$ Casación Laboral n. ${ }^{\text {o }}$ 7945-2014.
} 
415 obreros, el $41 \%$ son contratados por la figura de locación de servicios, el $37.1 \%$ por el régimen laboral privado, el $13.7 \%$ por el régimen laboral público y el $8.2 \%$ por el régimen de contratación administrativa de servicios (Instituto Nacional de Estadística e Informática [INEI], 2018). Esta inestabilidad en la contratación bajo diversos regímenes vulnera derechos laborales, al desobedecer lo estipulado en el art. 37 de la LOM (Servir, 2012).

Dilucidada la problemática, y con el afán de dar sustento a la presente, se identificaron algunos trabajos. En el ámbito nacional, se identificaron varios trabajos de interés: Vargas (2015) quien realizó su estudio en la municipalidad de Huanta; Cueva (2018) estudió la municipalidad de San Juan de Lurigancho; y Rojas (2017), la municipalidad de San Isidro. En el ámbito internacional, se encontraron los trabajos de Neira y Rojas (2016), que estudiaron las municipalidades de Chile; y Castillo (2019), analizó el Gobierno Autónomo Descentralizado Municipal de Loja (Ecuador). Todos estos estudios evidenciaron que existen diferentes tipos de contratación que vulneran los derechos de los TOM. Entre las principales vulneraciones se encontraron la ausencia de vacaciones, el trabajo realizado los fines de semana y feriados sin remuneración regulada normativamente, entre otros.

En ese sentido, el presente trabajo se realizó en el marco de una tesis, formulado y sustentado en la Facultad de Derecho y Ciencias Políticas de la Universidad Nacional Toribio Rodríguez de Mendoza de Amazonas (Perú), y tuvo como objetivo demostrar que las modalidades de contratación en obreros municipales han generado una problemática a nivel nacional. Se pretende identificar los derechos laborales que se vulneran en la contratación de obreros en MPCh durante los años 2017 y 2018, analizando los contratos suscritos entre el obrero y la MPCh. Asimismo, se procura resaltar la importancia de brindar un enfoque científico a la realidad de contratación de los obreros municipales. Además, se busca que los gobiernos locales puedan observar este panorama tan vulnerable y se orienten a adoptar las medidas correctivas necesarias para la regulación jurídica del obrero en las entidades del gobierno estatal, de tal modo evitar impactos negativos en la protección de derechos laborales y beneficios sociales al mismo.

\section{Marco jurídico, una línea de tiempo}

El problema descrito no es reciente, este tiene sus antecedentes dentro del plano normativo peruano desde hace muchos años atrás. Taxativamente, desde la época republicana con la publicación de leyes específicas en materia de contratación y protección laboral de TOM.

El 12 de mayo de 1978 se anuncia la publicación del Decreto Supremo 010-78-IN, donde se estableció que todos los obreros que prestaban servicios a Concejos Municipales del Estado pertenecerían al régimen laboral privado. En 1984 se publicó la Ley 23853, mediante el cual el 
Estado peruano decidió regular el funcionamiento de las municipalidades. Además, en la misma ley se dispuso que los obreros de las municipalidades a nivel nacional deberían ser reconocidos como servidores públicos sujetos exclusivamente al régimen laboral público.

A saber, la Ley 23853 establecía que los obreros municipales deberían pertenecer al régimen laboral de la actividad pública, pero que los derechos y beneficios que se les otorgaría serían los del régimen laboral privado. Esta disposición se consideró como inaplicable por tener inexactitudes con el D. S. n. ${ }^{\circ}$ 010-78-IN, dejando desamparado a miles de obreros municipales de la época. Luego, el Congreso peruano al advertir el error desarrollado en la Ley 23853, el 01 de junio de 2001 se dispuso a modificarla, publicando la Ley 27469, para establecer que los trabajadores obreros municipales serían considerados como servidores públicos, pero sin lugar a duda estarían sujetos al régimen laboral de la actividad privada.

En el año 2003 se publicó la Ley 27972 (Ley Orgánica de Municipalidades, LOM), que en su art. 37 determina que los trabajadores que prestan servicios como obrero en las municipalidades del país son considerados servidores públicos, pero sujetos al régimen laboral privado, en donde es más factible el reconocimiento de derechos y beneficios laborales. Dicha ley tiene vigencia desde el día siguiente de su publicación hasta la actualidad.

Finalmente, en el año 2018 mediante la publicación de la Ley 30889 (ley que precisa el régimen laboral de los obreros de los Gobiernos Regionales y Gobiernos Locales), se dispuso que los trabajadores obreros de los gobiernos locales y regionales se rigen por el régimen laboral privado del D. L. 728, estableciendo un único régimen y una norma específica para su aplicación.

\section{Metodología propuesta}

La investigación materia de análisis se basó en un diseño no experimental, de tipo descriptivo (Hernández, Fernández \& Baptista, 2014). Consistió en realizar recolección, registro y descripción de los resultados con la finalidad de conocer la naturaleza y la afectación de derechos laborales en la contratación de trabajadores obreros de la MPCh.

La población se conformó por los 54 contratos suscritos entre obreros y la MPCh durante los años 2017 y 2018. Para el desarrollo del presente se ha considerado el estudio del total de la población; es decir, los 54 contratos.

Las técnicas e instrumentos utilizados en la recolección de datos se basaron en el análisis documental, fichaje y observación directa. Se analizó los contratos de obreros en la MPCh a la luz de los derechos laborales observados en la legislación nacional. A saber, el D. L. 728, el D. S. 0001-97-TR, la Ley 25129, la Ley 27735, la Ley 26790, el D. S. 010-2003-TR, Ley 27972, 
Ley 30889 y Reglamentos Internos de trabajadores en la MPCh, además de fundamentar con opiniones y sentencias emitidas por el TC, así como la CSJ.

\section{Análisis efectuado a contratos de trabajadores obreros en la MPCh}

\section{Modalidades de contratación}

En 2017 y 2018, solo el $7.1 \%$ y $16.7 \%$, respectivamente, de los contratos se encuentran regulados por el régimen que según ley corresponde a un TOM; es decir el D. L. 728 (Figura 1). En ambos años de análisis, la mayor proporción de contratos estuvo regulada por el régimen laboral del D. L. 276 o régimen público.

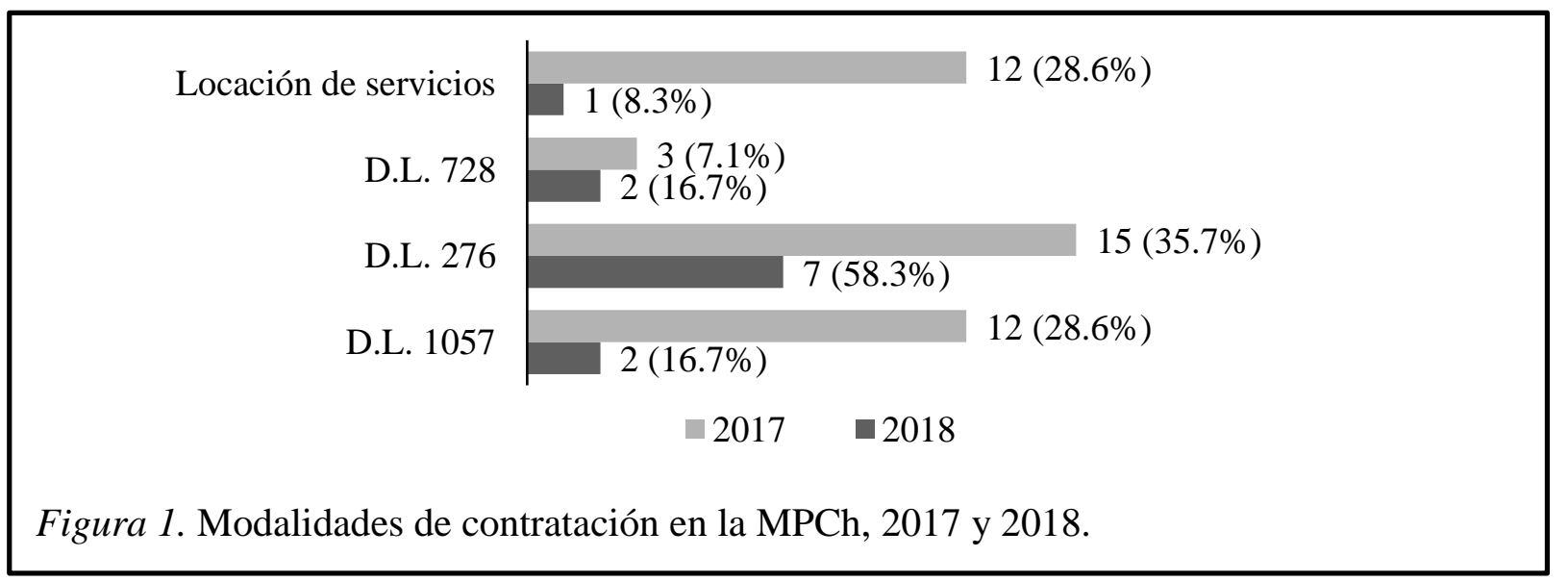

\section{Contratación por cargos}

En 2017 y 2018, solo el $2.4 \%$ y el $8.3 \%$, respectivamente, fueron contratos de policía municipal, guardián y limpieza y mantenimiento (figura 2).

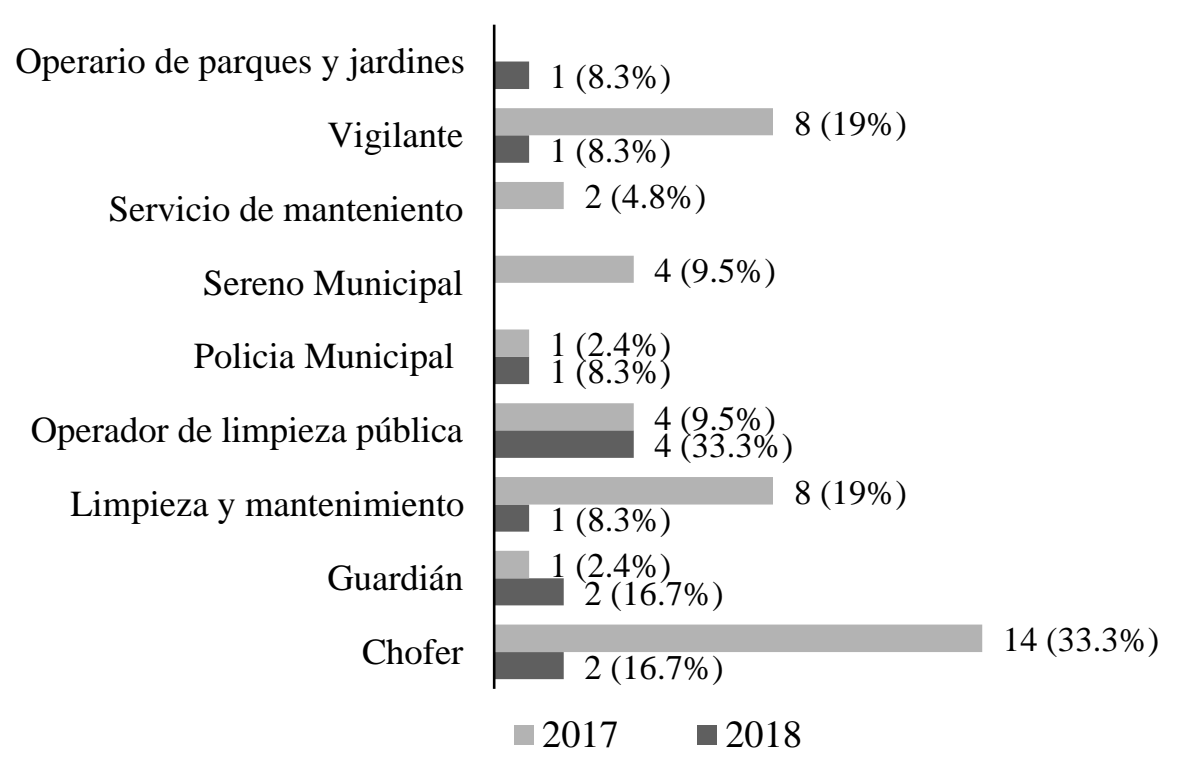

Figura 2. Modalidades de contratación en la MPCh, 2017 y 2018. 


\section{Adendas y/o renovaciones}

En la modalidad del D. L. 728 el $40 \%$ de los contratos se han referido a un tiempo de prueba que corresponde a un año. En la modalidad CAS, el $78.6 \%$ ha tenido al menos una adenda. En la modalidad del D. L. 276, el $9.1 \%$ ha tenido al menos una renovación. Por locación de servicios, el $23.1 \%$ ha tenido al menos una renovación (figura 3 ).

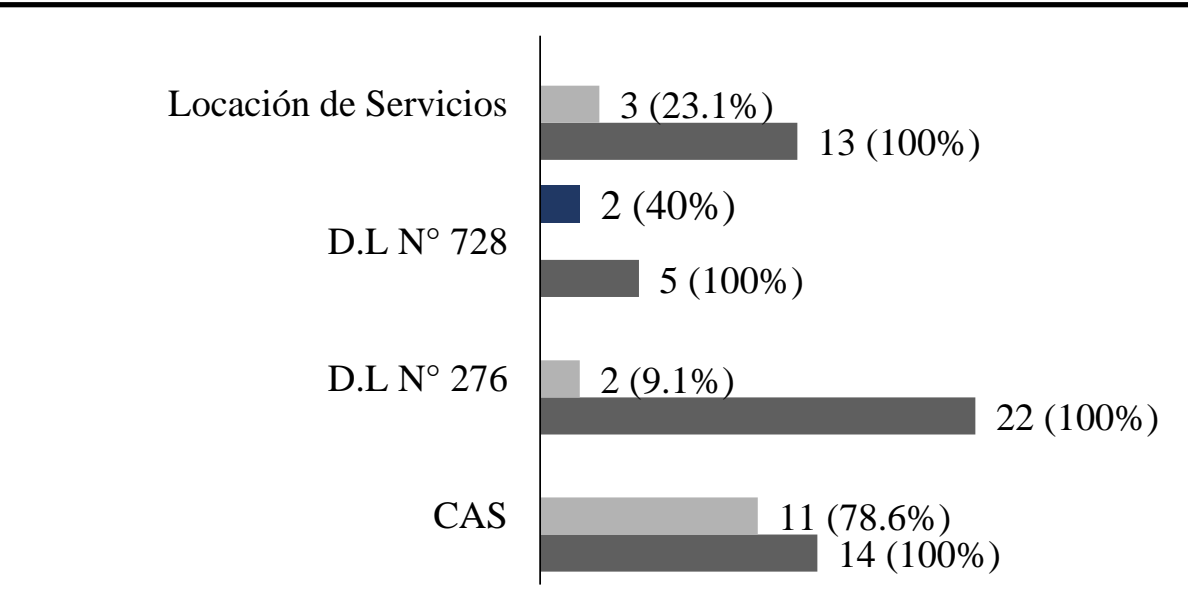

- Período de prueba $\quad$ Contrato con adendas / renovado $\quad$ Contrato principal

Figura 3. Renovación de contratos como locación de servicios, 2017 y 2018.

\section{Compensación por tiempo de servicios (CTS)}

En 2017, el $47.6 \%$ de los trabajadores recibió el depósito de CTS; sin embargo, por la contratación interrumpida de estos, no se depositaron completos, el $28.6 \%$ no especifica el depósito de CTS y el 23.8 \% han recibido los depósitos conforme a la ley. En 2018, el 75 \% recibió los depósitos conforme a la ley, el 16.7 \% recibió el depósito de CTS interrumpido y el $8.3 \%$ no especifica (figura 4).

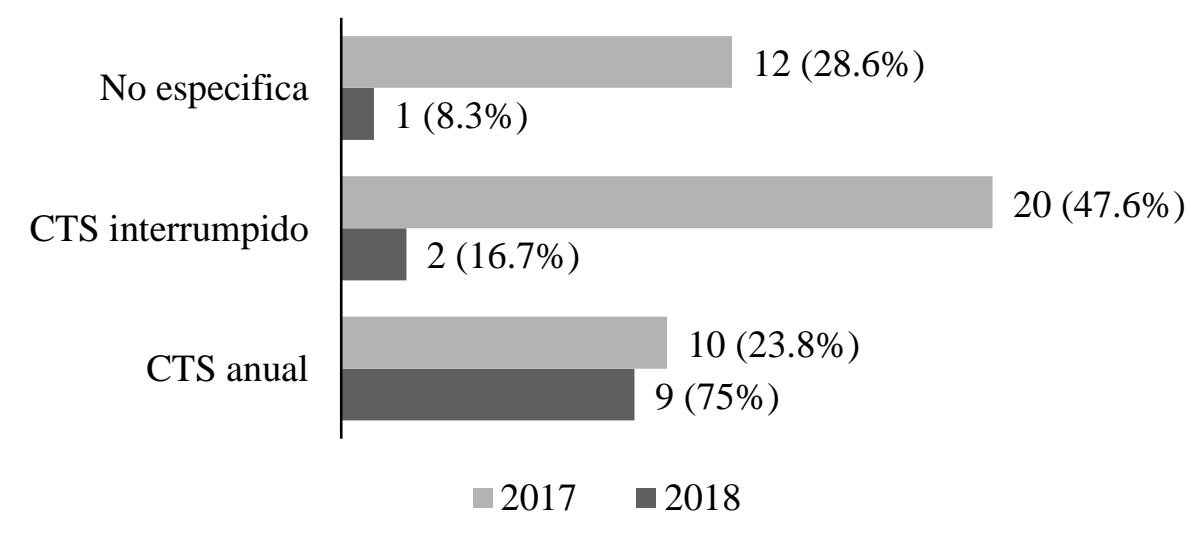

Figura 4. Compensación por tiempo de servicios en contratos de la MPCh, 2017 y 2018. 


\section{Asignación familiar}

En 2017, el $83.3 \%$ de los contratos no especifica si se otorga o no una asignación familiar y el $16.7 \%$ sí dispone una conforme a la ley. En 2018, el $92.9 \%$ no especifica una asignación familiar y el $7.1 \%$ dispone una conforme a ley (figura 5).

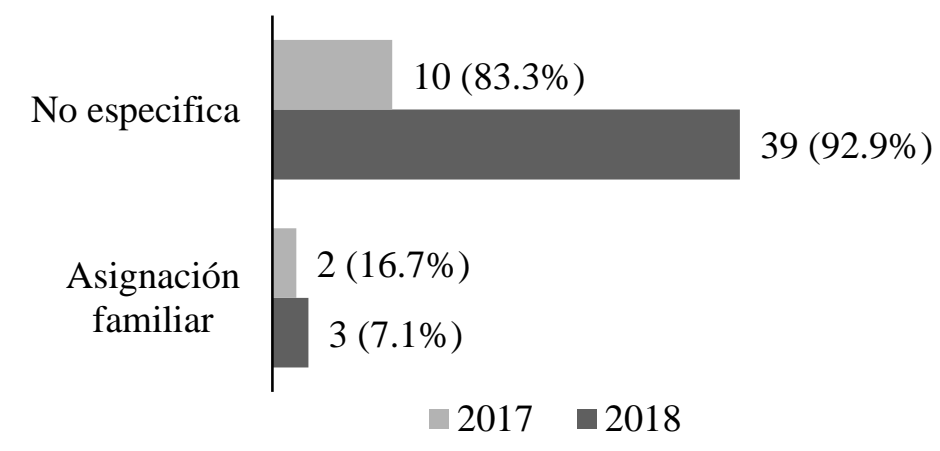

Figura 5. Asignación familiar de contratos en MPCh, 2017 y 2018.

\section{Gratificaciones}

En 2017, el 64.3\% de los contratos regula el depósitos de aguinaldos, el $28.3 \%$ no especifica depósitos y el 7.1 \% regula el depósito de gratificaciones; es decir, dos gratificaciones al año, una en julio, por concepto de fiestas patrias, y otra en diciembre, por fiestas navideñas. En 2018, el $75 \%$ regula depósitos de aguinaldos, el 16.7 \% regula el depósito de gratificaciones y el $8.3 \%$ no especifica (figura 6).

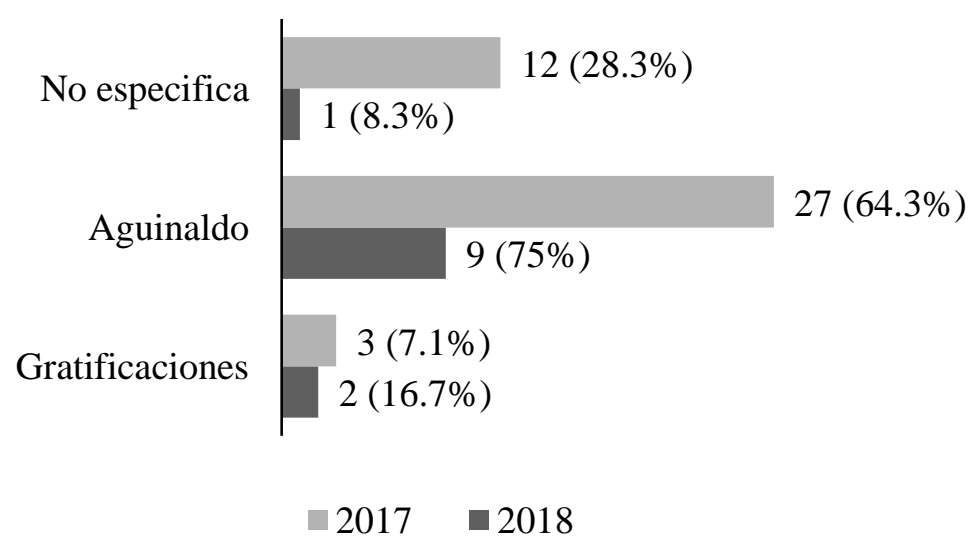

Figura 6. Gratificaciones de contratos en MPCh, 2017 y 2018. 


\section{Análisis de contratos}

En este apartado corresponde analizar los contratos de TOM suscritos con la MPCh durante los años 2017 y 2018. Los resultados obtenidos en el apartado precedente ahora se plasmarán en tablas para ser comparados. Para entender mejor las tablas mostradas subsiguientemente, se señala que: en la columna 1 se ubican los derechos a analizar; en la columna 2 se desarrolla la modalidad por la que el obrero fue contratado en la MPCh, pudiendo ser por D. L 1057, D. L. 276 o inclusive por la figura de locación de servicios; en la columna 3 se ubica la modalidad que le corresponde a un obrero, que es el D. L. 728; en la columna 4 se determina la vulneración de derechos laborales, teniendo en cuenta los derechos laborales otorgados bajo la modalidad contratada en la MPCh (D. L. 1057, D. L. 276 o inclusive la figura de locación de servicios) y los derechos laborales otorgados bajo la modalidad que efectivamente le corresponde a un obrero según la ley; en la columna 5 se avaló los resultados mediante la jurisprudencia y casos concretos.

En ese sentido, en la tabla 1 analiza la contratación de los obreros en la MPCh, 2017 y 2018, bajo la modalidad de contratación administrativa de servicios o también conocida como CAS. Se identificó como derechos vulnerados la estabilidad laboral y el pago de algunos beneficios sociales, como son las gratificaciones, compensación por tiempo de servicios (CTS) y asignación familiar. 
Tabla 1.

Análisis de los 14 contratos en la modalidad CAS 2017 y 2018 en la MPCh

\begin{tabular}{|c|c|c|c|c|}
\hline \multirow{2}{*}{ 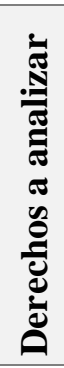 } & \multirow[t]{2}{*}{$\begin{array}{l}\text { ¿Cómo regula la } \\
\text { modalidad CAS? }\end{array}$} & \multirow[t]{2}{*}{$\begin{array}{c}\text { ¿Cómo regula la } \\
\text { modalidad del D. L. } \\
728 ?\end{array}$} & $\begin{array}{c}\text { ¿Vulnera } \\
\text { derechos } \\
\text { contratar } \\
\text { por el } \\
\text { CAS? }\end{array}$ & \multirow[t]{2}{*}{ Precedentes vinculantes } \\
\hline & & & Sí No & \\
\hline 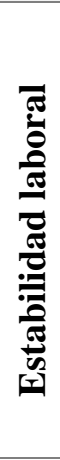 & $\begin{array}{l}\text { Contrato especial, } \\
\text { de naturaleza } \\
\text { temporal que no } \\
\text { cumple con los } \\
\text { requisitos básicos } \\
\text { de estabilidad }\end{array}$ & $\begin{array}{l}\text { Se tiene un período de } \\
\text { prueba, de } 3 \text { a } 6 \text { meses, } \\
\text { superado el tiempo } \\
\text { establecido, el } \\
\text { trabajador alcanza el } \\
\text { derecho a la } \\
\text { estabilidad laboral. }\end{array}$ & $\mathbf{X}$ & $\begin{array}{l}\text { Sentencia CAS. LAB. n. }{ }^{\mathbf{1 0 5 0 5}-2013} \\
\text { Que, los efectos de la contratación CAS } \\
\text { han sido anulados de plano, } \\
\text { convirtiéndose automáticamente en } \\
\text { trabajador obrero a plazo indeterminado, } \\
\text { sujeto al régimen de la actividad } \\
\text { privada; no habiéndose tomado en } \\
\text { cuenta que los contratos CAS } \\
\text { celebrados. }\end{array}$ \\
\hline \multirow{5}{*}{ 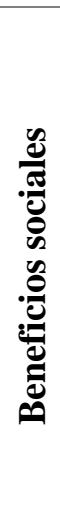 } & $\begin{array}{l}30 \text { días de } \\
\text { vacaciones* }\end{array}$ & 30 días de vacaciones & $\mathbf{X}$ & \multirow{5}{*}{$\begin{array}{l}\text { Exp. n. } .^{0} \text { 00030-2017-PA/TC } \\
\text { Interpuesto contra la municipalidad de } \\
\text { Carabayllo de Desnaturalización de } \\
\text { Contrato Administrativa de Servicios, } \\
\text { suscrito con la demandada, solicitando } \\
\text { beneficios sociales correspondientes al } \\
\text { período de } 2015 \text { y } 2016 \text { bajo el concepto } \\
\text { de reintegración de gratificaciones por } \\
\text { fiestas patrias y navidad y la asignación } \\
\text { familiar. }\end{array}$} \\
\hline & 2 aguinaldos al año & 2 gratificaciones al año & $\mathbf{X}$ & \\
\hline & $\begin{array}{l}\text { Seguro social de } \\
\text { salud }\end{array}$ & Seguros sociales & $\mathbf{X}$ & \\
\hline & No regula & CTS & $\mathbf{X}$ & \\
\hline & No regula & Asignación familiar & $\mathbf{X}$ & \\
\hline
\end{tabular}

Notas: * Los 14 contratos suscritos bajo el CAS en 2017 y 2018 tienen una duración menor a 10 meses. Elaboración propia en base a la ficha de análisis documental elaborada y aplicada, 2020. 
La tabla 2 muestra que el derecho más vulnerado en los contratos bajo la modalidad del D. L. 276 (régimen laboral público) es la estabilidad laboral, debido a que 10 de los contratos suscritos bajo esta modalidad tienen una duración de 3 meses, la cuarta cláusula de los contratos establece que la vigencia de estos es temporal. Además, se vulnera el derecho a los beneficios sociales, como son las gratificaciones y las asignaciones familiares.

Tabla 2.

Análisis de los 1o contratos en la modalidad del D. L. 276 en 2017 y 2018 en la MPCh

\begin{tabular}{|c|c|c|c|c|c|}
\hline \multirow{2}{*}{ 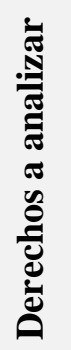 } & \multirow[t]{2}{*}{$\begin{array}{c}\text { ¿Cómo regula la } \\
\text { modalidad del D. L. } \\
276 ?\end{array}$} & \multirow[t]{2}{*}{$\begin{array}{c}\text { ¿Cómo regula la } \\
\text { modalidad del D. L. } \\
728 ?\end{array}$} & \multicolumn{2}{|c|}{$\begin{array}{c}\text { ¿Vulnera } \\
\text { derechos } \\
\text { contratar } \\
\text { por el D. L. } \\
\quad 276 ?\end{array}$} & \multirow[t]{2}{*}{ Precedentes vinculantes } \\
\hline & & & $\mathbf{S i}$ & No & \\
\hline 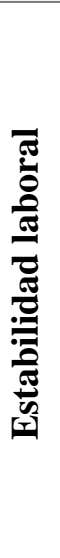 & $\begin{array}{l}\text { Renovación de contrato } \\
\text { hasta por } 3 \text { años seguidos, } \\
\text { pasado ese tiempo } \\
\text { podrían ingresar a la } \\
\text { carrera administrativa } \\
\text { como nombrados. Los } \\
\text { contratos de los TOM en la } \\
\text { Municipalidad Provincial } \\
\text { de Chachapoyas solo } \\
\text { tienen la condición de } \\
\text { contratados. }\end{array}$ & $\begin{array}{l}\text { Se tiene un periodo } \\
\text { de prueba, de } 3 \text { a } 6 \\
\text { meses, superado el } \\
\text { tiempo establecido, } \\
\text { el trabajador alcanza } \\
\text { el derecho a la } \\
\text { estabilidad laboral. }\end{array}$ & $\mathbf{X}$ & & $\begin{array}{l}\text { Exp. } \text { n. 06681-2013-PA/TC }^{\mathbf{0}} \text { Al contratarse bajo } \\
\text { modalidades diferentes estaría } \\
\text { vulnerando el derecho a la } \\
\text { estabilidad laboral. Pudiendo } \\
\text { solo ser contratados por el } \\
\text { régimen privado, de lo } \\
\text { contrario se estaría } \\
\text { desconociendo la evolución de } \\
\text { las normas que la regulan. }\end{array}$ \\
\hline \multirow{5}{*}{ 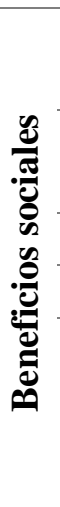 } & 30 días de vacaciones & $\begin{array}{l}30 \text { días de } \\
\text { vacaciones }\end{array}$ & & $\mathbf{X}$ & \multirow{5}{*}{$\begin{array}{l}\text { Exp. n. }{ }^{\circ} \text { 07166-2013-PA/TC } \\
\text { No puede considerarse eventual } \\
\text { la naturaleza de las labores que } \\
\text { realizó la accionante, toda vez } \\
\text { que, conforme al artículo } 4 \text { del } \\
\text { TUO del D. L. 728, la actora } \\
\text { tenía una relación laboral a } \\
\text { plazo indeterminado con } \\
\text { derechos inherentes a dicho } \\
\text { régimen. }\end{array}$} \\
\hline & 2 aguinaldos al año & $\begin{array}{l}2 \text { gratificaciones al } \\
\text { año }\end{array}$ & $\mathbf{X}$ & & \\
\hline & Seguro social salud & Seguros sociales & $\mathbf{X}$ & & \\
\hline & CTS & CTS & & $\mathbf{X}$ & \\
\hline & Bono por escolaridad & Asignación familiar & $\mathbf{X}$ & & \\
\hline
\end{tabular}

Notas: 10 de los contratos suscritos bajo esta modalidad, en 2017 y 2018 tienen una duración de 3 meses. La cuarta cláusula de los contratos, establece que la vigencia de estos es temporal. Elaboración propia en base a la ficha de análisis documental elaborada y aplicada, 2020. 
La tabla 3 muestra que los derechos más vulnerados en la contratación por locación de servicios son la estabilidad y los beneficios sociales, como gratificaciones, compensación por tiempo de servicios y asignación familiar. Además, se debe tener en cuenta que en las cláusulas de los contratos se detalla que la figura de locación de servicios no genera vínculo laboral ni reconoce derechos laborales, sino más bien se encuentra comprendido y protegido por las normas del Código Civil, del cual emerge solo una relación de naturaleza civil, mas no laboral.

Tabla 3.

Análisis de 13 contratos por la figura de locación de servicios en 2017 y 2018 en la $M P C h$

\begin{tabular}{|c|c|c|c|c|}
\hline 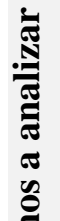 & $\begin{array}{l}\text { ¿Cómo regula la } \\
\text { locación de } \\
\text { servicios? }\end{array}$ & $\begin{array}{l}\text { ¿Cómo regula la } \\
\text { modalidad del } \\
\text { D. L. } 728 ?\end{array}$ & $\begin{array}{l}\text { ¿Vulnera } \\
\text { derechos } \\
\text { contratar } \\
\text { locación? }\end{array}$ & Precedentes vinculantes \\
\hline & & & $\mathbf{S i}$ & \\
\hline 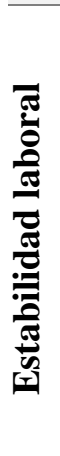 & $\begin{array}{l}\text { Considerado } \\
\text { como una } \\
\text { prestación de } \\
\text { naturaleza civil, } \\
\text { sin vínculo } \\
\text { laboral; por lo que } \\
\text { no regula tal } \\
\text { derecho. }\end{array}$ & $\begin{array}{l}\text { Se tiene un periodo } \\
\text { de prueba, de } 3 \text { a } 6 \\
\text { meses, superado el } \\
\text { tiempo establecido, } \\
\text { el trabajador } \\
\text { alcanza el derecho } \\
\text { a la estabilidad } \\
\text { laboral. }\end{array}$ & $\mathbf{X}$ & $\begin{array}{l}\text { Exp. n.0 00142-2016-0-1618-JM-LA-01 } \\
\text { Resulta innegable que el tener } \\
\text { estabilidad en el empleo le permite } \\
\text { planificar y presupuestar con cierto } \\
\text { grado de certidumbre. En consecuencia, } \\
\text { al estar en una relación laboral a plazo } \\
\text { indeterminado solo corresponde el } \\
\text { despido con causa justa establecida en la } \\
\text { ley. }\end{array}$ \\
\hline & $\begin{array}{l}\text { No regula el } \\
\text { reconocimiento ni }\end{array}$ & $\begin{array}{ll}30 & \text { días } \\
\text { yacaciones }\end{array}$ & $\mathbf{X}$ & $\begin{array}{l}\text { Exp. n. }{ }^{\circ} \text { 00698-2017-PA/TC, } \\
\text { SULLAA }\end{array}$ \\
\hline 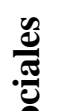 & $\begin{array}{l}\text { pago de } \\
\text { beneficios }\end{array}$ & $\begin{array}{l}2 \text { gratificaciones al } \\
\text { año }\end{array}$ & $\mathbf{X}$ & $\begin{array}{l}\text { Para determinar si existió una relación } \\
\text { de trabajo entre las partes se evalúa si en }\end{array}$ \\
\hline 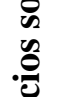 & sociales & Seguros sociales & $\mathbf{X}$ & $\begin{array}{l}\text { los hechos se presentó en forma } \\
\text { alternativa y no concurrente, }\end{array}$ \\
\hline فำ & & $\begin{array}{l}\text { Compensación por } \\
\text { tiempo de servicios }\end{array}$ & $\mathbf{X}$ & $\begin{array}{l}\text { reconociendo derechos laborales, como } \\
\text { vacaciones, gratificaciones y descuentos }\end{array}$ \\
\hline & & Asignación familiar & $\mathbf{X}$ & $\begin{array}{l}\text { para los sistemas de pensiones y de } \\
\text { salud. }\end{array}$ \\
\hline
\end{tabular}

Nota: Elaboración propia en base a la ficha de análisis documental elaborada y aplicada, 2020. 


\section{Discusión de los resultados}

Los resultados obtenidos han sido similares a los resultados obtenidos por Vargas (2015), quien evaluó la contratación de obreros en el municipio de Huanta, logrando demostrar que el $33.70 \%$ de los obreros se encuentran contratados por el régimen público, un $30.43 \%$ bajo el régimen privado, un $29.35 \%$ por locación de servicios y un $6.52 \%$ por el régimen de CAS. Además, cifras recogidas por el INEI al 31 de marzo de 2018 indican que a nivel nacional existe un total de 69.046 obreros, donde el $2 \%$ son nombrados y el $1.4 \%$ son contratados bajo el D. L. 276, el $54 \%$ bajo el D. L. 728, el $18 \%$ bajo el régimen especial CAS y el $24.6 \%$ por la figura de locación de servicios (INEI, 2018). Demostrando que la problemática no es solo en la MPCh, sino a nivel nacional. En Chile, Neira y Rojas (2016) lograron determinar la existencia de un elevado porcentaje de contratación a honorarios en las municipalidades chilenas, deviniendo en irregular y poniendo en peligro la observancia al orden público laboral.

Como ya se precisó en el apartado del marco jurídico, la contratación de personal en la administración pública es una problemática que se ha venido arrastrando desde la época republicana en los varios intentos de homogeneizar un régimen laboral único para los servidores estatales, específicamente para los obreros en los municipios del país.

\section{¿Se vulnera el derecho a la estabilidad laboral?}

Toyama (2015) define el derecho a la estabilidad laboral como la conservación y permanencia del contrato de trabajo. En la Legislación Nacional, la protección de este derecho se puede ver reflejado desde la Carta Magna en su artículo 27 (CPP, 1993) donde precisa que la norma concede amparo al empleado frente al despido arbitrario.

Bajo las premisas dilucidadas y los resultados obtenidos, se ha confirmado la existencia de contratos administrativos de servicios (CAS), contratos bajo el régimen público (D. L. 276) y contratos bajo la figura de locación de servicios que fueron suscritos de manera mensual, por hasta un año fiscal, el cual a la larga ha conllevado a una vulneración del derecho a la estabilidad laboral. Esto manifiesta que la Municipalidad Provincial de Chachapoyas, con un porcentaje elevado, ha dado preferencia a contratos de naturaleza determinada, contratos que solo cumplen un papel secundario y temporal.

Cabe destacar que en el análisis efectuado a los contratos bajo el régimen laboral privado (D. L. 728) ha evidenciado que estos durante dos años consecutivos (2017 y 2018) han desarrollado funciones de la misma naturaleza; es decir, funciones que solo 
competen a un obrero municipal, pero que el perfeccionamiento contractual ha sido de manera temporal, aun teniendo en cuenta que en esta modalidad de contratación solo se requiere que el obrero supere los 3 y como máximo 6 meses del período de prueba para que automáticamente se reconozca como trabajador a tiempo indeterminado. Con ello se demuestra la infracción a lo dispuesto en el artículo 43 del D. L. 728, dejando en un estado de vulnerabilidad que no solo puede perturbar su derecho a la estabilidad laboral, sino otros derechos, entre ellos el pago de sus beneficios sociales.

Estos resultados también se justifican con lo sustentado por Pacaya, Taminchi y Ruiz (2018), quienes en su investigación realizada en la municipalidad de Campoverde, periodo 2015, concluyeron que el régimen laboral por el cual se contrata a obreros afecta en gran medida el derecho a una estabilidad laboral, toda vez que se observa la inobservancia del artículo 37 de la LOM. Asimismo, Zavala (2018) menciona que la contratación de un obrero bajo una modalidad distinta a la dispuesta por ley vulnera la estabilidad laboral, puesto que la contratación se realiza de manera temporal y con una duración regular (renovable) por el lapso de un año. Esta situación impide el desarrollo laboral y personal, creando incertidumbre y discriminación a las oportunidades laborales.

Por otro lado, Heredia (2018) logró determinar la vulneración de la estabilidad laboral bajo el régimen privado del D. L. 728, esta vulneración se configuró con el despido arbitrario a los TOM de la municipalidad distrital de Yanacancha. El despido se concretó sin que medie causa justa y sin dar oportunidad al trabajador a contradecir su legalidad. De este modo, el derecho a una estabilidad laboral se ha visto limitada, pues el despido arbitrario no ha permitido que la relación laboral entre la entidad y el trabajador se reconozca como permanente, quedando esta relación en dependencia única y excepcionalmente de la entidad o municipio y dejando desprotegido al obrero.

\section{¿Se vulnera el derecho de otorgar beneficios sociales?}

En la doctrina internacional, está el Código del Trabajo de Chile, que desarrolla ampliamente los beneficios sociales, al detallar que estos favorecen a trabajadores comprendidos en la Legislación Nacional Laboral, además de constituir garantías que pueden ser reformadas con el vínculo de trabajo entre el trabajador y la institución (contrato de trabajo y/o convenios colectivos).

Cueva (2018) identificó que la desnaturalización de los contratos por la figura de locación de servicios en los policías municipales de San Juan de Lurigancho afecta gravemente en el pago de los beneficios sociales, debido a que el $50 \%$ de los policías 
municipales no vienen percibiendo ningún beneficio social, como es el goce de su descanso vacacional de 30 días por año trabajado, que además es reconocido por ley.

Por su parte, Vásquez (2018) dice que este derecho es totalmente irrenunciable, además que de la misma Constitución deslinda el derecho a un descanso semanal y anual remunerados y al disfrute de su compensación. Asimismo, Aranda (2019) colige que todas las personas tienen derecho a un trabajo digno, la cual comprende que el empleador reconozca derechos laborales inherentes a cada trabajador. Ante estos hechos, se considera absurdo que en un estado constitucional de derecho, que además es firmante de varios tratados internacionales de derechos laborales, se desarrollen este tipo de casos. Sin embargo, conforme se ha desarrollado, esta problemática no solo se ve reflejada en las municipalidades a nivel local, sino a nivel internacional acorde con lo desarrollado en la investigación de Castillo (2019) en el Gobierno Autónomo Descentralizado Municipal de Loja (Ecuador), que evidencia la vulneración de derechos laborales en los afiliados del Sindicato de Obreros Municipales de Loja. Entre las vulneraciones más destacadas encontró el no otorgamiento de vacaciones, trabajo fines de semana y feriados sin remuneración legal, por lo que esta vulneración ocasiona graves afectaciones a nivel del trabajador.

En ese contexto, los obreros de la MPCh al encontrarse contratados bajo modalidades distintas y no encontrándose sujetos a un régimen laboral fijo se limitan a gozar del derecho a la estabilidad laboral y al reconocimiento de beneficios sociales. Esto principalmente puede verse influenciado por la ausencia de ciertas políticas institucionales, entre ellas la ausencia de un reglamento exclusivo que regule la situación jurídica-laboral y las condiciones a las que debe sujetarse durante su desempeño, todo ello en marco de lo dispuesto en el régimen laboral privado.

Acorde a lo desarrollado, queda claro que la evolución histórica de los regímenes laborales que acogen a los obreros y la ausencia de políticas institucionales devienen en factores predeterminantes en cuanto a la contratación en la Municipalidad Provincial de Chachapoyas. De igual modo, Tirado (2018) señala que la vulneración de derechos y beneficios laborales en la Municipalidad Distrital de La Esperanza se da por diversos constituyentes, uno de ellos es que el municipio no cuenta con la disponibilidad presupuestal para cubrir las plazas, así como el poco interés que le dan a capacitar al personal trae consigo conflictos laborales, que a la larga generan gastos para la institución. Los municipios prefieren no otorgar los beneficios laborales como corresponde y prefieren contratar bajo una modalidad diferente. 
Al no cumplir con estos beneficios se estaría excluyendo del cumplimiento expreso dispuesto en la normativa, pues por algunas medidas arbitrarias de las entidades, estas no reconocen derechos y beneficios a los trabajadores obreros, prefiriendo una contratación que no otorga derechos ni beneficios, o si los otorga son reducidos. Llegando incluso a configurarse la discriminación hacía la persona, infringiendo el principio de igualdad, establecido en el artículo 26 de la Carta Magna (CPP, 1993).

En este caso, la MPCH al contratar a un тOM bajo el D. L. 276, D. L. 1057, CAS y la figura de locación de servicios, estaría desmereciendo la modalidad contractual dispuesta en el artículo 37 de la LOM, la cual debe brindar protección y procurar el respeto al trabajador sin condición legal alguna.

\section{Desafíos actuales}

En las municipalidades a nivel nacional se evidencia el grave problema, deficiencia en cumplir y poner en práctica la disposición indicada en la Ley Orgánica de Municipalidades (Ley 27972), fallos jurisprudenciales emitidos por el Tribunal Constitucional y otros órganos de justicia competentes. El Estado a la fecha cuenta con una ineficaz gestión funcionaria respecto a la contratación de obreros municipales, ya que los servidores y funcionarios presiden especialmente la decisión de la autoridad municipal, ya que es el funcionario superior de la gestión en desarrollo.

Esto podría conllevar a la imposición de demandas laborales y, como en la mayoría de los conflictos, el Poder Judicial aplica efectivamente el principio protector al derecho laboral. Sin embargo, el cumplimiento de la sentencia se prolonga mucho más porque en gran medida las municipalidades tienen la convicción de dar prioridad y cumplir con las sentencias en proceso y no con las que ya se encuentran en ejecución (Denegri, 2018). Esto llegaría a generar una mayor penalidad y con ello una deuda pecuniaria elevada, en la que cada gestión continua. Por lo que se considera indispensable que las municipalidades tengan el conocimiento pleno de sus faltas y procurar trabajar por beneficiar a la colectividad y aplicar lo legal y legítimamente reconocido a toda persona, el respeto por sus derechos laborales y su dignidad ante situaciones de vulneración. Además, que cada entidad gestione de manera progresiva, la regulación jurídica de los obreros contratados por modalidades diferentes a las dispuestas por ley. 


\section{Conclusiones}

Se ha logrado identificar que la municipalidad en estudio estaría incumpliendo con lo establecido en la Ley 27972 y la Ley 30889 al contratar obreros bajo las modalidades de la contratación administrativa de servicios (D. L. 1057), D. L. 276 (actividad pública) e incluso bajo la figura de locación de servicios (contrato civil), generando una vulneración de derechos laborales, como la estabilidad laboral y el pago de beneficios sociales, entre ellos vacaciones, compensación por tiempo de servicios, gratificaciones y asignación familiar.

Esta problemática no solo se desarrolla es en la Municipalidad Provincial de Chachapoyas, sino en las municipalidades a nivel nacional e incluso en el ámbito internacional, trayendo consigo la vulneración de derechos laborales y constitucionales, demandas laborales e incluso deudas pecuniarias. Por lo que en ese contexto se recomienda que cada entidad procure trabajar por aplicar lo legal y legítimamente reconocido. Además, que cada entidad gestione de manera progresiva la regulación jurídica de los obreros contratados por modalidades diferentes.

\section{Referencias}

Aranda, M. (2019). La estabilidad laboral frente al despido por pérdida de confianza del trabajador que ingresó directamente al cargo (Tesis de grado). Universidad Nacional de Trujillo, Perú.

Autoridad Nacional del Servicio Civil [Servir]. (2012). Aplicación del régimen de contratación administrativa de servicios a regímenes especiales. Informe Legal $N^{\circ}$ 330-2012-SERVIR/GG-OAJ. Lima: Servir.

Castillo, A. (2019). Vulneración de los derechos laborales a los miembros del sindicato de obreros municipales de Loja; en el GAD municipal (Tesis de grado). Universidad Nacional de Loja, Ecuador.

Constitución Política del Perú [CPP]. (1993). Diario Oficial el Peruano. Lima, Perú.

Cueva, R. (2018). La desnaturalización de los contratos de locación de servicios de los Policías Municipales de la Municipalidad de San Juan de Lurigancho, 2017 (Tesis de grado). Universidad César Vallejo, Perú.

Denegri, G. (2018). El contrato laboral del trabajador obrero municipal y la vulneración de sus derechos en la Municipalidad de Carabayllo 2017 (Tesis de grado). Universidad César Vallejo, Perú. 
Heredia, T. (2018). Vulneración de la estabilidad laboral en el régimen privado D. $L$. 728 y el despido arbitrario en la Municipalidad Distrital de Yanacancha, provincia de Pasco, 2016 (Tesis de grado). Universidad Nacional de Huánuco, Perú.

Hernández S., Fernández C., \& Baptista, L. (2014). Metodología de la investigación (6ta ed.). México: McGraw-Hill.

Instituto Nacional de Estadística e Informática [INEI]. (2018). Perú: Indicadores de Gestión Municipal 2018. Lima: INEI.

Ministerio de Trabajo y Promoción del Empleo [MTPE]. (2016). Compendio de normas sobre la legislación laboral del Régimen Privado (5ta ed.). Lima: MTPE.

Neira, F., \& Rojas, A. (2016). Trabajadores a honorarios. La municipalidad como transgresor del orden público laboral. Revista Chilena de Derecho del Trabajo y de la Seguridad Social, 7(13), 53-83.

Organización Mundial del Trabajo [OIT]. (2009). La Organización Internacional del Trabajo y la lucha por la justicia social, 1919-2009. Ginebra: OIT.

Pacaya, M.; Taminchi, K., \& Ruiz, L. (2018). El régimen laboral de las municipalidades y su afectación a la estabilidad laboral de los trabajadores municipales en la Municipalidad Distrital de Campo Verde durante el periodo 2015. (Tesis de grado). Universidad Nacional de Ucayali, Perú.

Rojas, W. (2017). Reconocimiento de los Derechos Laborales del Trabajador del Serenazgo y sus implicancias en el Régimen de la Actividad privada del Decreto Legislativo $N^{o} 728$ (Tesis de grado). Universidad de Huánuco, Perú.

Tirado, J. (2018). Los beneficios sociales de los trabajadores bajo el régimen 728 de las Municipalidades del Perú: caso Municipalidad Distrital de la Esperanza, 2017 (Tesis de grado). Universidad Católica los Ángeles de Chimbote, Perú.

Toyama, M. (2015). El derecho individual del trabajo en el Perú: Un enfoque teóricopráctico. Lima: Gaceta Jurídica.

Tribunal Constitucional [TC]. (2015). Sentencia del Tribunal Constitucional. Expediente $N^{\circ}$ 05577-2015-PA/TC. Huánuco: TC.

Vargas, P. (2015). Contratación de obreros en Regimenes Laborales en la Municipalidad Provincial de Huanta (Tesis de grado). Universidad Nacional San Cristobal de Huamanga, Perú.

Vásquez, M. (2018). El contrato de servicios de terceros y el derecho a la estabilidad laboral en la Sociedad de Beneficencia de Lima Metropolitana del año 20162017 (Tesis de grado). Universidad César Vallejo, Perú.

Zavala, L. (2018). ¿La regla de Derecho debe prevalecer sobre el Principio Jurídico Laboral? Análisis del Contrato Administrativo de servicios. Vox Juris, 36(2), 171-201. 


\section{Contribución autoral}

a) Concepción y diseño del trabajo; b) Adquisición de datos; c) Análisis e interpretación de datos; d) Redacción del manuscrito; e) revisión crítica del manuscrito.

Y.S.R.R. ha contribuido en a, b, c, d, e; y P.M.C.D. en a, c, e.

Editora científica responsable: Dra. María Paula Garat. 